Esta obra está bajo una Licencia Creative Commons

Atribución-NoComercial-Compartirlgual 4.0 Internacional

El trabajo docente en una Universidad del Bicentenario: ámbitos y estrategias

de enseñanza para el fortalecimiento de las trayectorias académicas estudiantiles

Lucía Petrelli

Trayectorias Universitarias, 7 (12), e060, 2021

ISSN 2469-0090 | https://doi.org/10.24215/24690090e060

https://revistas.unlp.edu.ar/TrayectoriasUniversitarias

Universidad Nacional de La Plata

La Plata | Buenos Aires | Argentina

\title{
El trabajo docente en una Universidad del Bicentenario: ámbitos y estrategias de enseñanza para el fortalecimiento de las trayectorias académicas estudiantiles
}

\author{
Educational work at a University of Bicentenary: teaching scope and \\ strategies for the strengthening of student academic paths
}

\author{
Lucía Petrelli \\ https://orcid.org/0000-0002-5047-4031 \\ petrellilucia@gmail.com \\ Universidad Nacional de José C. Paz
}

\section{RESUMEN}

Este artículo avanza en la caracterización del trabajo docente en una Universidad del Bicentenario: la Universidad Nacional de José C. Paz. Desde un enfoque socioantropológico o etnográfico se documentan las formas en que se desarrollan las interacciones, los climas y los modos en que los docentes convocan al trabajo con los contenidos en dos ámbitos institucionales diferenciados: un Taller de Metodología de estudio de carácter optativo y una materia troncal que forma parte del plan de estudio de la Licenciatura en Trabajo Social. La descripción analítica de los procesos de enseñanza en esos espacios, del cómo del hacer, permite advertir una interesante dinámica de producción situada de compromisos y legitimidades que estaría potenciando las estrategias docentes en términos de generar una inserción cada vez más plena de los estudiantes en la vida universitaria.

\section{ABSTRACT}

This article advances on the featuring of educational work at a University of Bicentenary: the University of José C. Paz. Based on a socioanthropological or etnographic stand, the paper documents manners of interaction, atmospheres and ways in which students are expected to work the contents in two different institutional areas: a) a workshop on Studying Methodology, optional subject in the Social Work career; b) a subject making part of the main line of the Social Work Career curricula. The analytic description of teaching processes in such areas, the how-to, shows interesting dynamics of production of commitment and legitimacy that appear to be strengthening educational worker strategies by helping students to get increasingly involved in university life.

PALABRAS CLAVE trabajo docente, universidad, enseñanza curricular, tutoría.

\section{KEY WORDS}

educational work, university, curricula teaching, tutorial classes. 


\section{PRESENTACIÓN}

La Universidad Nacional de José C. Paz comenzó a funcionar hace aproximadamente una década. Como otras casas de estudio creadas en ese entonces en territorio bonaerense, ha permitido acceder a la educación superior a un sector de la población que no lo había hecho previamente. Desde el inicio de su historia, la inclusión se ha presentado como fundamento y enorme desafío.

Interesada en el despliegue cotidiano de esa impronta inclusiva y enfocándome particularmente en los procesos de enseñanza inicié, ya hace algún tiempo, una caracterización del trabajo docente en distintos espacios institucionales que apuntan al fortalecimiento de las trayectorias académicas de los estudiantes. Se trata de instancias heterogéneas y que persiguen ese objetivo a través del trabajo con las prácticas de lectura y escritura, la metodología de estudio o directamente con contenidos disciplinares. Considero que esta variedad de dispositivos y propuestas tiene que ser leída en el marco de un proceso más amplio en el que va complejizándose cada vez más la ya de por sí heterogénea educación superior, no solo en la Argentina sino en el mundo, y en la que "la pregunta por la democratización del conocimiento supone no prestar solo atención a la facilitación del acceso a nuevos saberes, sino y sobre todo a los contextos formativos y los proyectos político-pedagógicos que se despliegan [...] a los procesos subjetivos individuales y colectivos" (Carli, 2018: 5).

\section{SEGUIR EL DESARROLLO DEL TALLER, LLEGAR A LA MATERIA}

Desde las orientaciones referidas y para avanzar en la dirección planteada, me propuse seguir el Taller de Metodología de estudio impulsado por la Licenciatura en Trabajo Social de la UNPAZ desde un enfoque socioantropológico o etnográfico (Achilli, 2005; Guber, 2006). Previamente, trabajé en identificar progresivamente cómo había surgido esta propuesta, quienes la habían motorizado, quienes la llevaban a la práctica y, eventualmente, cómo se había ido transformando 
ya que entiendo que los dispositivos tienen que ser siempre historizados (Petrelli y Cabrera, 2019).

Acompañé entonces el desarrollo de la totalidad de los encuentros desde la observación participante y publiqué, recientemente, un primer análisis de esa experiencia (Petrelli, 2020). Aquí me interesa recuperar sintéticamente las cuestiones más relevantes para ponerlas en diálogo con lo que acontece en el marco de una asignatura obligatoria. La posibilidad de estar ahí, en el Taller, me permitió acceder a interacciones de primera mano, percibir climas al momento de realizar las tareas, reconocer formas en que la tutora convocaba al trabajo con los contenidos. Pero, centralmente, me llevó a pensar que lo primordial que allí ocurría era la producción de vínculos. El Taller era un espacio de encuentro en el que se iban forjando relaciones que, advertí luego, en ocasiones tenían historia: algunos estudiantes conocían a la tutora por haber cursado con ella en el ciclo de inicio a la universidad, por haber asistido a espacios individualizados de tutoría a su cargo, y hasta por haber participado previamente del mismo Taller de Metodología de estudio el año anterior. Comprendí entonces que este dispositivo debía ser reflexionado como parte de un circuito más amplio por el que transitaban los estudiantes y que se configuraba incluyendo no sólo propuestas de apoyo o acompañamiento sino también espacios curriculares del ciclo de inicio y del primer año de la carrera de Trabajo Social.

La mención a una materia troncal de primer año de la carrera como parte de ese entramado exige reponer que la propuesta de trabajo del Taller toma como recursos para ejercitar las técnicas de estudio textos obligatorios de la asignatura cuya lectura, perciben los docentes, resulta muy dificultosa para los estudiantes. En el Taller, los encuentros giraban en torno de textos extraídos del programa de la asignatura con la que articulaba. La docente tutora, por lo general, iba guiando los intercambios grupales sobre lo leído y presentando distintas estrategias para que los estudiantes pudieran acceder al material. Los invitaba, por ejemplo, a que observaran el título y reflexionaran sobre la información que aportaba, que recorrieran los distintos apartados y sus subtítulos, que ubicaran conceptos clave, ideas principales, etc. También, que volvieran sobre el programa de la materia para ubicar el texto que tenían entre manos en la unidad correspondiente, los contenidos que en ella se proponía trabajar para reflexionar, desde ahí, acerca del por qué habría sido incluido. Sin embargo, lo que a mi juicio estructuraba la convocatoria al trabajo con estos textos y técnicas tenía que ver con la interpelación a los estudiantes como parte de un sujeto colectivo que, al ingresar a un nuevo ámbito académico/disciplinar, requiere familiarizarse con algunas de las pautas que estructuran ese universo y entrenarse para moverse con soltura en él. En esta apelación, ubicaba a los distintos participantes como parte de un todos (los ingresantes a la universidad y a Trabajo Social) y no como indivi- 
duos aislados que carecen de un saber por incapacidades propias. De modo complementario, interpreto que ese tipo de apelación operaba al mismo tiempo legitimando el espacio de tutoría, en ese caso, bajo la modalidad de taller.

\section{La mención a una materia troncal de primer año de la carrera como parte de ese entramado exige reponer que la propues- ta de trabajo del Taller toma como recursos para ejercitar las técnicas de estudio textos obligatorios de la asignatura cuya lectura, perciben los docentes, resulta muy dificultosa para los estudiantes.}

Guiada por la idea de un circuito más amplio por el que transitaban los estudiantes, e interesada centralmente en el desarrollo de los procesos de enseñanza en los múltiples sitios que lo configuraban, resolví extender el referente empírico de mi investigación y acompañar, en esta segunda etapa, el dictado de una unidad de esta materia troncal. Al igual que en las observaciones realizadas en el Taller, me preocupé especialmente por registrar cuidadosamente no solo qué se les proponía hacer a los estudiantes en uno y otro ámbito sino cómo se los convocaba, entendiendo que el trabajo docente consiste justamente "en [ese] "convocarlos a trabajar" sobre actividades que [se] les propone, con la esperanza de que se conviertan en contextos que faciliten el aprendizaje, en "andamiajes"(...) que conduzcan hacia nuevos conocimientos o habilidades" (Rockwell, 2013: 454).

En el caso de la materia, las estrategias se desplegaban a través del uso de distintos recursos (videos, imágenes, textos) que, se esperaba, habilitaran que a los estudiantes les "hiciera sentido" el contenido central de la asignatura, vinculado a la historia del Trabajo Social. En este punto, me interesa detenerme en el modo en que se usaban algunos de estos recursos. Hallé que recurrentemente se proponían actividades de escritura individual en clase, con consignas que apuntaban a la articulación de lo leído/oído/visto en un video o en imágenes, con los núcleos trabajados por los autores. Así, presencié una actividad que consistió inicialmente en la lectura del prólogo de un libro sobre una experiencia de desarrollo rural de una comunidad, escrito por la entonces Ministra Carolina Standley. A continuación, se solicitó a los estudiantes que intentaran identificar ideas desarrollistas en el texto y las volcaran por escrito. Luego, se proyectó un video en el que distintas trabajadoras sociales reponían la experiencia que se estaba realizando en un complejo habitacional de la CABA. Una vez finalizado el video, se propuso a los cursantes que escribieran un texto de dos párrafos en el que vincularan lo visto con lo que habían estado trabajando sobre 
el desarrollismo. Se conversó acerca de la dificultad del ejercicio dado que, en este segundo caso, el desarrollismo no aparecía de modo tan explícito como en el caso del prólogo. Las docentes recogieron al final de la jornada los escritos y anunciaron que los estarían entregando la clase siguiente. En esa nueva jornada, destinaron por lo menos tres cuartos de hora a la devolución de los escritos a través de comentarios generales. Observé que una de las profesoras desarrollaba su relato preguntando a los estudiantes si se identificaban en algunas de las situaciones descritas. Cuando eso ocurría, daba la palabra para que cada quien leyera su producción a modo de ejemplificación. Ese día, la reflexión se cerró en comentarios que iban en distintas dimensiones pero que se articulaban: los sentidos y usos de la escritura en el marco de la profesión; la necesidad de trabajarla, entonces, para que lo que queramos plantear -como profesionales- sea comprendido sin inconveniente; la idea de que trabajar aspectos formales de la escritura en clase (cuestiones de sintaxis, oraciones subordinadas) es trabajar también contenidos disciplinares, etc. Pese a que interpreté las prácticas de las docentes en términos de una clara convicción respecto de la pertinencia de desarrollar estas ejercitaciones en clase, advertí también que por momentos entendían necesario legitimarlas ante los estudiantes: "la idea no es transformar esto en una clase de lengua pero sí seguir trabajando en la apropiación de contenidos a partir de la escritura" (Nota de campo octubre de 2019).

Las prácticas de lectura y escritura promovidas por las docentes de la comisión resultaban cruciales en la movilización de los saberes de los estudiantes (Carli, 2012: 6) que, al verse en situación de volcar por escrito, volvían sobre lo leído, lo vinculaban con escenas de la vida cotidiana y con los recursos heterogéneos puestos a disposición por las docentes. Progresivamente, fui comprendiendo que era ese un contexto en el que la escritura se enseñaba "entrelazada en las materias" (Carlino, 2018).

\section{Guiada por la idea de un circuito más amplio por el que tran- sitaban los estudiantes, e interesada centralmente en el de- sarrollo de los procesos de enseñanza en los múltiples sitios que lo configuraban, resolví extender el referente empírico de mi investigación y acompañar, en esta segunda etapa, el dictado de una unidad de esta materia troncal.}

Retomando en este punto la intención inicial de caracterizar procesos de enseñanza en distintos espacios institucionales en relación al mandato inclusivo fundante de universidades como la UNPAZ, considero queTaller (voluntario) y espacio áulico de una materia curricular (obli- 
gatorio) presentaban ciertas continuidades. Sucede que en este mirar lo que hacen los docentes en uno u otro ámbito, el cómo del hacer, es que advierto que las prácticas se orientan hacia una inserción cada vez más plena de los estudiantes a la vida universitaria. Por otro lado, las dinámicas propuestas y formas de convocar, e incluso las formas de explicitar ante sus auditorios las razones que justifican el trabajo en una dirección u otra, habían sido aprendidas en sitios que hasta ahora no mencioné y que reunían a las docentes a cargo de la comisión y a la docente tutora que sostenía el Taller: me refiero concretamente a espacios de formación docente desarrollados en el marco de la universidad.

Sucede que en este mirar lo que hacen los docentes en uno u otro ámbito, el cómo del hacer, es que advierto que las prácticas se orientan hacia una inserción cada vez más plena de los estudiantes a la vida universitaria.

Como los estudiantes, las docentes también parecen haber ido configurando su hacer a partir de la circulación por espacios heterogéneos al interior de la universidad: las aulas de las materias curriculares y los espacios de taller o tutoría, las instancias de trabajo impulsadas desde la coordinación de la carrera y/o desde áreas dentro de la Secretaría Académica o distintas propuestas de capacitación docente en torno de la lectura y la escritura académica, son algunos de los sitios que van entramándose y configurando circuitos que se tornan formativos y se potencian entre sí. Es en esta circulación, y en los encuentros con otros que van teniendo lugar, que los docentes configuran o ajustan sus estrategias y formas de convocar a los estudiantes al trabajo con los contenidos. Desde luego, lo hacen en función de quienes son, de sus historias de formación y trabajo, de sus biografías (Petrelli, 2018 y 2019); y en relación a lo que van sabiendo sobre los estudiantes que son sus interlocutores.

Como los estudiantes, las docentes también parecen haber ido configurando su hacer a partir de la circulación por espacios heterogéneos al interior de la universidad: las aulas de las materias curriculares y los espacios de taller o tutoría, las instancias de trabajo impulsadas desde la coordinación de la carrera y/o desde áreas dentro de la Secretaría Académica o distintas propuestas de capacitación docente en torno de la lectura y la escritura académica, son algunos de los sitios que van entramándose y configurando circuitos que se tornan formativos y se potencian entre sí. 
Finalmente y respecto de las características que asume el trabajo docente en universidades atravesadas por la impronta inclusiva, me interesa dejar planteado que el hacer de los profesores conlleva la tarea de presentar -y legitimar- ante los estudiantes los distintos espacios de acompañamiento o apoyo, sugerir recorridos posibles entre unos y otros, y enfatizar su carácter articulado (por lo menos en términos de intencionalidad político/institucional). En este sentido, los docentes son gestores de esos espacios al promoverlos, más allá de si se desempeñan en materias curriculares o extracurriculares.

\section{A MODO DE CIERRE}

En este artículo avancé en la caracterización del trabajo docente en una Universidad del Bicentenario: la Universidad Nacional de José C. Paz. Desde un enfoque socioantropológico o etnográfico comencé documentando las formas en que se desarrollan las interacciones, los climas y los modos en que la docente a cargo del Taller de Metodologĺa de estudio convoca al trabajo con los contenidos. Encontré que esa convocatoria se estructura en una apelación a los estudiantes como parte de un sujeto colectivo que, al ingresar a un nuevo ámbito académico/disciplinar, requiere familiarizarse con algunas de las pautas que estructuran ese universo y entrenarse para moverse con soltura en él. Desde esa impronta, se tejen y redefinen vínculos y compromisos entre estudiantes y tutora que parecen impactar, simultáneamente, en la legitimación del espacio de tutoría en su modalidad de Taller.

A continuación, me detuve en la descripción de lo que acontecía en el marco de una asignatura obligatoria de la Carrera de Trabajo Social que articulaba con el Taller antes mencionado. Describí sintéticamente aspectos de lo que se les proponía a los estudiantes y cómo se los convocaba. Hallé que frecuentemente era mediante actividades de escritura individual en clase que se buscaba que los estudiantes fueran amalgamando los contenidos trabajados en la bibliografía, lo visto/leído/oído en materiales variados que las docentes seleccionaban para complementar los textos obligatorios, sus propias biografías... En diversas situaciones registré que insistían en que trabajar aspectos formales de la escritura en clase es también trabajar contenidos disciplinares aunque, junto con ello, advertí que por momentos entendían necesario legitimarlas ante los estudiantes ("la idea no es transformar esto en una clase de lengua").

La descripción analítica de los procesos de enseñanza en esos espacios, del cómo del hacer, permite advertir una interesante dinámica de producción situada de compromisos y legitimidades que estaría potenciando las estrategias de las profesoras implicadas en términos de generar una inserción cada vez más plena de los estudiantes a la vida universitaria. 


\section{BIBLIOGRAFÍA}

Achilli, E.L. "Investigar en antropología social: los desafíos de transmitir un oficio". Rosario: Laborde Editor. 2005.

Carli, S. (2018). “Hacia una revisión crítica de la enseñanza universitaria. Tendencias, experiencias y desafíos en torno al conocimiento en las universidades públicas". Trayectorias Universitarias. Volumen 4, No 6. 2018. Disponible en: https://revistas.unlp.edu.ar/TrayectoriasUniversitarias/article/view/5978

Carlino, P. (2018). “Dos variantes de la alfabetización académica cuando se entrelazan lectura y escritura en las materias". Signo y Pensamiento, 36 (71). 2018. Disponible en: https://www.aacademica.org/paula.carlino/241

Fernández Álvarez, M.I.; Gaztañaga, J. y Quirós, J. (2017). “La política como proceso vivo: diálogos etnográficos y un experimento de encuentro conceptual". Revista Mexicana de Ciencias Políticas y Sociales, vol. LXII, num.231. 2017. Disponible en: https://www.redalyc.org/pdf/421/42152785011.pdf

Guber, R. (2006). "La etnografía. Método, campo y reflexividad". Buenos Aires: Editorial Norma. 2001. 9. Lahire, B. El espíritu sociológico. Buenos Aires: Manantial.

Quirós, J. (2014). “Etnografiar mundos vívidos. Desafíos de trabajo de campo, escritura y enseñanza de la antropología". Publicar en Antropología y Ciencias Sociales, Año XII N XVII. 2017. Disponible en: http://ppct.caicyt.gov.ar/index. php/publicar/article/view/4914

Petrelli, L. y Cabrera, V. (2019). “La política como método de investigación: las tutorías como analizador de relaciones y regulaciones en la vida universitaria". En Revista Argentina de Educación Superior 11, UNTREF, 2019. Disponible en: http://www.revistaraes.net/revistas/raes19_art4.pdf

Petrelli, L. (2018). “Enfoque biográfico, interpelaciones institucionales y tiempos superpuestos: notas para pensar trayectorias de docentes". En Actas I Jornadas Democracia y Desigualdades. 2018 Disponible en: https://www.unpaz. edu.ar/sites/default/files/2019-06/28-32-PB.pdf

Petrelli, L. (2018). “Trabajo docente y procesos de inclusión en la Universidad Nacional de José C. Paz: enseñanza, dispositivos institucionales de acompañamiento y líneas ad hoc". En Goren, N. e Isacovich, P. (comps) El trabajo en el conurbano bonaerense. Actores, instituciones y sentidos. José C. Paz: Edunpaz. 2018. Disponible en: https://edunpaz.unpaz.edu.ar/OMP/index.php/edunpaz/ catalog/view/14/20/55-2 
Rockwell, E. (2013). “El trabajo docente hoy: nuevas huellas, bardas y veredas". En XI Congreso Nacional de Investigación Educativa. Consejo Mexicano de Investigación Educativa. 